\title{
(Re) Organização do cotidiano de indivíduos com doenças crônicas a partir da estratégia de grupo
}

\author{
Alessandra Antunes Tavares ${ }^{a}$, Luciana Mata de Freitas ${ }^{a}$, \\ Fabiana Caetano Martins Silva ${ }^{\text {b }}$ Rosana Ferreira Sampaio ${ }^{c}$ \\ ${ }^{a}$ Terapeuta Ocupacional, Universidade Federal de Minas Gerais - UFMG, Belo Horizonte, MG, Brasil \\ bDoutora em Ciências da Reabilitação, Programa de Pós-Graduação em Ciências da Reabilitação, \\ Universidade Federal de Minas Gerais - UFMG, Professora Adjunta, Departamento de Terapia Ocupacional, \\ Universidade Federal do Triângulo Mineiro - UFTM, Uberaba, MG, Brasil \\ 'Doutora em Saúde Pública, Universidade Autônoma de Barcelona, Professora Associada, \\ Departamento de Fisioterapia, Programa de Pós-Graduação em Ciências da Reabilitação, \\ Universidade Federal de Minas Gerais - UFMG, Belo Horizonte, MG, Brasil
}

\begin{abstract}
Resumo: A prevalência e incidência das doenças crônicas vêm aumentando significativamente na população, impactando aspectos físicos e o âmbito social e pessoal. As intervenções direcionadas a pacientes crônicos devem ser capazes de abranger esses fatores. Atendimentos grupais podem se tornar uma estratégia de intervenção para esta população. A Terapia Ocupacional utiliza em sua prática o atendimento a pacientes crônicos através do modelo grupal, ancorado na estratégia de educação em saúde. Neste contexto, o objetivo do estudo foi documentar a percepção dos indivíduos com doenças crônicas sobre as mudanças de comportamentos diários a partir da participação em um grupo de educação em saúde. Para tanto, entrevistaram-se indivíduos com doenças crônicas participantes do "Grupo de Orientação e Autocuidado a Indivíduos Acometidos por Doenças Crônicas". Este estudo se insere no campo da pesquisa qualitativa e a técnica metodológica utilizada para a coleta de dados foi entrevista semiestruturada. Evidenciou-se, através dos relatos, que o grupo assumiu significados distintos para os participantes: espaço de socialização, lazer e de cuidado; espaço incentivador de mudança; e espaço para o conhecimento do processo de adoecimento e das diferentes formas de lidar com a incapacidade. Quando os integrantes do grupo compreendem suas limitações e potencialidades, passam a enfrentar os problemas advindos da doença, tornando-se agentes ativos da própria mudança. Assim, o grupo tornou-se lócus importante para a reconstrução da vida de cada participante, auxiliando-os no desenvolvimento de estratégias de enfrentamento, capazes de proporcionar uma nova reorganização da vida cotidiana.
\end{abstract}

Palavras-chave: Doenças Crônicas, Estrutura de Grupo, Educação em Saúde, Atividades Cotidianas, Terapia Ocupacional.

\section{(Re) Organization of daily life of individuals with chronic diseases based on group strategy}

\begin{abstract}
The prevalence and incidence of chronic diseases have increased significantly among the population, creating physical, social and personal impacts. Interventions directed to chronic patients ought to be able to cover these factors. Group activities can become an intervention strategy for this population. In its practice, occupational therapy utilizes care services to chronically affected patients through group models, based on the strategy of health education. In this context, the purpose of this research was to document the perception of individuals with chronic disease conditions on changes in daily behaviors, through the participation in a group of health education. To this end, interviews were conducted with individuals affected by chronic diseases, participants of
\end{abstract}

Autor para correspondência: Fabiana Caetano Martins Silva, Rua Professor Manoel Casassanta, 420, ap. 201, Ouro Preto, CEP 31310-590, Belo Horizonte, MG, e-mail: fabianacmartins@yahoo.com.br

Recebido: 24/10/2011; 1ª Revisão: 12/12/2011; Aceite final: 30/1/2012. 


\begin{abstract}
"The Group of Guidance and Self-care to Individuals Affected by Chronic Diseases". This study is part of the field of qualitative research and the methodological approach using semi-structured interviews for data collection was used. The reports demonstrated that the guidance group has different meanings for the participants: space for socialization, recreation and care; space that encourages change; and space for the knowledge of the illness process and the different ways of coping with inability. When group members understand their potential and limitations, they start to face the problems caused by the diseases and become active agents of change themselves. In this way, the group has become an important locus for the reconstruction of all participants' lives, helping them to develop strategies capable of providing a new reorganization of everyday life.
\end{abstract}

Keywords: Chronic Diseases, Group Structure, Health Education, Activities of Daily Life, Occupational Therapy.

\title{
1 Introdução
}

A prevalência e incidência das doenças crônicas vêm aumentando significativamente na população em geral, principalmente nos países em desenvolvimento, representando $60 \%$ de todo ônus decorrente de doenças no mundo (ORGANIZAÇÃO..., 2005). Estas produzem morte prematura, afetam a qualidade de vida dos indivíduos e trazem repercussóes econômicas, sociais, emocionais e familiares, prejudicando a qualidade de vida do sujeito (ORGANIZAÇÃO..., 2005). Atualmente, as doenças crônicas constituem uma grande preocupação para os profissionais da área da saúde, seja pelos aspectos limitantes ocasionados ou pelo desgaste e sofrimento da pessoa acometida (MARCON et al., 2005).

As doenças reumáticas são consideradas condiçôes crônicas de saúde e a maioria delas produz grave prejuízo nas funçóes do corpo, no envolvimento em atividades básicas significativas e na participação no trabalho e lazer (LAURINDO et al., 2002; SILVA et al., 2011). A artrite reumatoide (AR) é a mais relatada tanto pela sua frequência quanto pelas implicaçôes funcionais significativas (CARVALHO; NOORDHOEK; SILVA, 2006). A osteoartrite, outra doença de caráter crônico, tem sua prevalência aumentada com o avanço da idade e afeta mais de $75 \%$ das pessoas com mais de 65 anos, sendo que $10 \%$ destas possuem limitaçóes físicas advindas da patologia. Fibromialgia, psoríase e lúpus também se enquadram neste grupo de condiçôes de saúde e também restringem significativamente a qualidade de vida dos pacientes (CABRAL; MONTANDON; SILVA, 2008). Limitaçóes no desempenho funcional advindas de possíveis deformidades e sintomas como dor, fadiga, rigidez e desgaste articular, diminuição de amplitude de movimento, redução de força, crepitaçóes, edema, dentre outros ocasionados por este grupo de doenças crônicas tornam-se frequentes no cotidiano desses indivíduos (YASUDA, 2005).

A reduçáo gradativa da produtividade e independência, além das incapacidades presentes ocasionam perdas no contexto pessoal, nos cuidados de saúde e no âmbito social, portanto, ao se avaliar indivíduos com doenças reumáticas, deve-se atentar para os comprometimentos em suas funçóes cotidianas (ASSUMPÇÃO; CAVALCANTI; SILVA, 2007; LOSCHIAVO; NOORDHOEK, 2005).

Considerando que estas doenças influenciam não somente aspectos físicos, mas também o âmbito social e pessoal, a intervenção voltada a esses indivíduos deve ser capaz de abranger essas características. Neste sentido, o acompanhamento em grupo, aliado ao acompanhamento dos profissionais da área $\mathrm{da}$ saúde, pode se tornar uma estratégia de intervenção para indivíduos com doenças crônicas, como as doenças reumáticas. Dessa forma, é fundamental a elaboração de estratégias de intervenção que possam ir além dos tratamentos clínicos e cirúrgicos, e sendo a educação em saúde através de um modelo grupal uma opção a ser considerada (MERLO; JACQUES; HOEFEL, 2001; CARVALHO; NOORDHOEK; SILVA, 2006; KERKOSKI et al., 2007). Segundo Feirenberg e Trombly (1995), a Terapia Ocupacional emprega, como uma das modalidades de intervenção, a educação ao paciente crônico através de um modelo grupal de intervenção, ancorado em programa educacional incluindo princípios de conservação de energia, técnicas de simplificação do trabalho, de proteção articular, dentre outros.

Fortes (2000) relata que um grupo é benéfico para indivíduos com doenças crônicas e destaca vários aspectos positivos: a experiência grupal rompe com o isolamento que essas pessoas normalmente vivenciam; torna-se um local para aprender a lidar com a dor, utilizando o aprendizado do outro como forma de ajuda, o que aumenta a rede social de apoio; se constitui em um espaço educativo capaz de promover esclarecimentos; auxilia no aprendizado da "fala", uma vez que esses indivíduos, por vezes, apresentam dificuldades para expressar sentimentos; além de possibilitar identificar e trocar experiência 
com os outros integrantes. Assim, o uso do grupo como estratégia de intervenção rompe com a lógica do modelo médico no qual o terapeuta é entendido como um expert, possibilitando aos integrantes assumirem um papel ativo no processo terapêutico, como agentes da própria mudança (BECHELLI; SANTOS, 2002). Desta forma, a força para a mudança provém dos próprios participantes do grupo, já que um integrante, ao se sentir motivado, fortalece o outro para que este se engaje na busca de transformaçóes. Neste sentido, práticas educativas em grupo vêm se tornando cada vez mais frequentes e valorizadas.

As intervenções em grupo auxiliam na educação para saúde, o que possibilita maior capacidade de enfrentamento da doença, resgate do senso de competência e mudanças que se estendem ao bem-estar físico e psíquico (CARVALHO; NOORDHOEK; SILVA, 2006). O grupo, além de potencializar as capacidades do sujeito, pode promover mudanças de comportamentos e atitudes direcionadas ao desenvolvimento da autonomia e ao enfrentamento das condiçóes que geram sofrimento (SANTOS et al., 2006). Dessa forma, o gerenciamento das condiçôes crônicas, como as doenças reumáticas, requer por parte do paciente, uma mudança no estilo de vida e de comportamentos diários (SILVA et al., 2011). Ou seja, o paciente tem um papel ativo, central em seu tratamento, sendo que a participação em grupo pode auxiliar nestas mudanças de comportamentos cotidianos.

Em adição, a ação grupal apresenta-se na perspectiva do reconhecimento das necessidades subjetivas e coletivas do indivíduo, permitindo a construção do cuidado em saúde (SENA; SILVA, 2008). Segundo Ayres (2004, p. 85),

[...] o cuidado ocorre a partir uma interaçáo entre dois ou mais sujeitos visando o alívio de um sofrimento ou o alcance de bem-estar, sempre mediada por saberes especificamente voltados para essa finalidade.

Nesta perspectiva, um grupo de intervenção é capaz de estimular o indivíduo participante a tornar-se o agente da própria mudança. Assim, ouvir o que os participantes têm a dizer a respeito das mudanças de comportamentos diários ocorridas após o ingresso em um grupo torna-se a centralidade do processo investigativo. Neste contexto, o objetivo deste estudo foi documentar a percepção dos indivíduos com doenças crônicas sobre as mudanças de comportamentos diários resultantes da sua participação em um grupo de intervenção.

\section{Percurso metodológico}

Este estudo utilizou metodologia qualitativa para analisar e interpretar os significados do grupo para os participantes e as mudanças de comportamentos em seu cotidiano. O grupo em questáo é chamado "Grupo de Orientação e Autocuidado a Indivíduos Acometidos por Doenças Crônicas" e se configura em um projeto de extensão do Departamento de Terapia Ocupacional da Universidade Federal de Minas Gerais (UFMG). Este grupo encontra-se semanalmente no Laboratório do Movimento, localizado na Faculdade de Medicina da UFMG desde 1996. Aproximadamente 30 participantes com diferentes doenças crônicas já participaram deste grupo desde a sua fundação.

Atualmente, o grupo conta com 15 pessoas e, destas, 11 aceitaram participar do presente estudo. A amostra foi composta por participantes de ambos os sexos, sendo 10 mulheres e um homem, com idade variando de 30 a 79 anos. Dentre estes, quatro participam do grupo a menos de três anos, dois fazem parte do grupo há cerca de sete anos, três participantes estáo envolvidos com as atividades deste grupo de educação em saúde há 11 anos e dois são participantes assíduos do grupo desde o início de suas atividades. Assim, todos os participantes da amostra faziam parte do grupo há pelo menos três meses, apresentavam frequência mensal regular, e consentiram voluntariamente em participar do estudo assinando o termo de consentimento livre e esclarecido, aprovado pelo Comitê de Ética em Pesquisa da UFMG (no ETIC 132/09). A técnica metodológica utilizada para a coleta de dados foi entrevista semiestruturada, cujas perguntas abordaram os comportamentos cotidianos dos participantes antes e depois do ingresso no grupo; se ocorreram mudanças nestes comportamentos após o seu ingresso e quais fatores consideram como desencadeadores destas mudanças, além da percepção a respeito da participação em um grupo de educação em saúde.

As entrevistas foram realizadas no local onde ocorrem os encontros semanais do grupo e foram gravadas em aparelho $\mathrm{MP}$, com autorização prévia dos participantes. Depois de sua realização, as entrevistas foram transcritas para recuperar a integralidade dos depoimentos e, em seguida, encaminhadas aos participantes para confirmação das informaçôes disponibilizadas.

Depois da realização e transcrição das entrevistas, estas foram analisadas a partir da "análise de conteúdo" por "unidades temáticas”, uma vez que, segundo Minayo (2004), a presença de determinados 
temas leva a valores de referência, além de modelos de comportamento presentes no discurso dos participantes do estudo. Esta análise foi desenvolvida em três etapas: pré-análise, na qual o objetivo inicial da pesquisa foi retomado e o material organizado em unidades temáticas relacionadas com as perguntas do roteiro; exploração do material, com realização de um recorte do texto em unidades de registro e posterior classificação e agregação da informação a partir de categorias teóricas identificadas na primeira etapa; e tratamento e interpretação dos resultados obtidos, colocando em destaque informaçóes que merecem discussão à luz da literatura (BARDIN, 1979). Na apresentação dos resultados deste estudo, os nomes dos participantes foram substituídos por pseudônimos para preservar as suas identidades.

\section{Resultados e discussão}

Os resultados deste estudo exploraram como os integrantes do "Grupo de Orientação e Autocuidado a Indivíduos com Doenças Crônicas" vivenciam sua participaçáo, e como o grupo auxilia estes participantes a modificarem comportamentos diários, objetivando melhor qualidade de vida.

A partir da análise de conteúdo das entrevistas, percebeu-se a presença de amplos temas envolvendo a relação doença crônica e cotidiano. Nas narrativas, foram identificados relatos que envolviam: 1) as dificuldades relacionadas com a condição crônica e o impacto destas nas atividades de vida diária; 2) o papel do grupo, descrito pelos participantes como um local de socialização, lazer, cuidado, aprendizado e orientação; 3) as mudanças ocorridas após o ingresso no grupo, destacando-se, em especial, o esforço dos indivíduos para modificar os hábitos de vida e a forma como realizar as atividades cotidianas; e, por fim, 4) o enfrentamento do adoecimento e da sua condição crônica. Estes diferentes aspectos observados nas entrevistas foram organizados em três principais categorias que proporcionam a análise do ponto de vista dos indivíduos acerca de suas participaçóes em um grupo de educação em saúde, fornecendo detalhes que permitem uma melhor compreensão das vivências e valores envolvidos neste processo. Para além, os relatos e as categorias encontradas evidenciam a importância de intervençôes grupais direcionadas a indivíduos com doenças crônicas, em especial, doenças reumáticas, com o objetivo de identificar prejuízos nas funçôes do corpo, no envolvimento em atividades básicas significativas e restriçốes no trabalho e lazer, buscando aumentar e potencializar a funcionalidade, o senso de competência e uma participação social plena.

\subsection{Impacto das doenças crônicas no cotidiano}

Grande parte dos indivíduos acometidos por doenças crônicas apresenta limitaçóes no desempenho funcional advindas de possíveis deformidades e sintomas como dor, fadiga, rigidez e desgaste articular, diminuição de amplitude de movimento, redução de força, crepitações, edema, dentre outros (YASUDA, 2005). Todos estes aspectos impactam fortemente no cotidiano, gerando limitaçôes durante a realizaçâo de tarefas do dia a dia, o que foi evidenciado nos relatos dos entrevistados:

"Sentia muita dor e chorava muito de tanta dor e não podia fazer nada. (...) A dor afetava qualquer parte do corpo, aí eu ficava paralisada, eu não aguentava caminhar" (Maria).

"As juntas inchavam, aí eu não tinha mais jeito de movimentar o braço" (Magda).

"Tinha rigidez, eu tinha inchaço nas mãos, nos punhos" (Heloisa).

Pode-se observar que a queixa mais frequentemente apresentada pelos participantes é a dor, a qual dificulta e, em alguns momentos, impede o indivíduo de realizar, de forma satisfatória, suas atividades cotidianas. A dor configura-se como um fenômeno multidimensional, referida como uma experiência sensorial e emocional desagradável associada a um dano real (MERSKEY; BOGDUK, 1994), e, quando evolui para o estado crônico, torna-se um problema de saúde pública. De acordo com o Ministério da Saúde (BRASIL, 2002), a dor crônica acomete cerca de 30 a $40 \%$ dos brasileiros, constituindo-se na principal causa de licenças médicas, indenização trabalhista e baixa produtividade no trabalho.

A dor crônica, quando não tratada, pode gerar complicaçôes como depressão, alteraçóes no sono, apetite, irritabilidade, agressividade, ansiedade, alteraçôes de energia, diminuição da capacidade de concentração, atenção e memória (comprometimento da função cognitiva), isolamento social e até mesmo incapacidades e diminuição da qualidade de vida (FEIRENBERG; TROMBLY, 1995). Percebe-se, desta forma, que a dor crônica pode gerar dificuldades funcionais, afetivas, comportamentais e sociais, impactando na execução de atividades de vida diária, trabalho e lazer (FEIRENBERG; TROMBLY, 1995; KRELING, CRUZ; PIMENTA, 2006; SILVA et al., 2011). Os fragmentos a seguir exemplificam o impacto da dor e dos outros sintomas decorrentes das condiçôes reumáticas no cotidiano destes indivíduos:

"A costura eu tive que parar e me aposentar por causa das dores" (Fátima). 
"Era dificuldade para lavar uma roupa, passar uma roupa, pentear meu cabelo" (Rosa).

"Eu não conseguia picar verdura, descascar uma abóbora" (Luzia).

"Até pra tomar café era difícil, não tava segurando a canequinha mais, ela caia, eu náo tinha força e doía muito" (Magda).

Ao analisar os relatos apresentados, observa-se que a dor é uma das principais causas do sofrimento entre os participantes, gerando incapacidades, comprometendo a qualidade de vida e repercutindo no âmbito psicossocial (BOTTEGA; FONTANA, 2010). Segundo Silva et al. (2011), a dor crônica implica em consequências na participação, levando a restriçóes representadas por perda dos papéis desempenhados e a sofrimento em relação às mudanças em seu cotidiano.

\subsection{Importância do grupo para mudanças do cotidiano}

O grupo torna-se um local de acolhimento da dor e do sofrimento apresentado por estes indivíduos. Nas narrativas analisadas, o grupo assume sentidos diferentes além do terapêutico, tais como local de socialização, lazer e espaço de cuidado. De acordo com os participantes entrevistados, o grupo tem como uma de suas funções, a promoção do lazer e da socialização:

"Quando você passa a conviver com as outras pessoas, com a mesma situação ou pior, você começa a perceber que seu problema não é único, você não é exclusiva naquilo que está vivendo" (Fátima).

"Sempre eu fico muito alegre, (...) vendo que tudo em grupo é melhor do que individual. (...) $\mathrm{O}$ apoio do grupo, sair de casa (...) conversar sobre suas dificuldades, o que tá acontecendo, parece que você melhora" (Luzia).

"A gente fez muitos amigos né, temos muitas amizades. Tem umas que eu ligo para elas, outras que eu vou à casa delas" (Rosa).

Segundo Dumazedier (1976), o lazer configura-se em uma série de ocupaçóes em que o indivíduo pode se entregar de livre vontade, apresentando três funçóes principais: descanso; divertimento, recreação e entretenimento; e desenvolvimento. Logo, o lazer pode trazer como benefícios a recuperação física e psicológica, fuga, extravasamento do agente estressor, desenvolvimento da personalidade e socialização. Para além, a Associação Mundial de Recreação e Lazer, através da Carta Internacional de Educação para o Lazer (WORLD..., 1993), aponta que o lazer inclui a liberdade de escolha, criatividade, satisfação, sendo uma forma de promoção da saúde, visto como um recurso para melhorar a qualidade de vida. Assim, o lazer oferece oportunidades que permitem ao sujeito escolher atividades que vão de encontro às suas necessidades e interesses. A satisfação torna-se a principal recompensa provocada pela participação em atividades de lazer, se mostrando um importante fator de mudanças tanto comportamentais, como moral e cultural (COSTA, 2008).

Neste contexto, o contato com outros participantes do grupo estimula a maior socialização dos integrantes e, consequentemente, este aspecto parece impactar positivamente na sua condição de saúde e bem-estar. De acordo com Bechelli e Santos (2002), o suporte social, ou seja, a busca pelo apoio em um amigo, parente ou colega, é essencial para o bem-estar pessoal, exercendo assim, importante papel como ferramenta de intervençáo. A socialização proporcionada pelo grupo também favorece a integração e estreita o relacionamento entre seus participantes. Um participante mais motivado fortalece outros integrantes a engajar-se de forma mais ativa na busca pela mudança e reorganização de seus hábitos. Em resposta, o apoio mútuo consolida a uniáo entre os indivíduos do grupo (BECHELLI; SANTOS, 2002). Sendo assim, em um grupo o indivíduo se identifica e desenvolve um aprendizado interpessoal a partir do contato com o outro.

Para além, o grupo ainda configura-se em um espaço de cuidado, de reconhecimento das necessidades subjetivas e coletivas, ou seja, um grupo constrói o cuidado a partir do conceito de integralidade, com enfoque individual e coletivo (SENA; SILVA, 2008). A seguir, são destacados alguns trechos relativos às açóes de acolhimento $\mathrm{e}$ cuidado que o grupo promove:

"No começo eu senti assim um acolhimento muito grande no grupo" (Maria).

"Há um conforto sim em saber que você não está sozinho nessa caminhada, (...) as palavras recebidas aqui, de consolo, não só da coordenadora, mas do grupo, dos outros pacientes também. Aí você pensa que não está sozinho" (Carlos).

Neste sentido, o acolhimento que o grupo proporciona torna-se intimamente ligado à integralidade. Hennington (2005) aponta que o acolhimento vai muito além da simples recepção de um indivíduo em um determinado serviço, mas engloba todas as questôes que antecedem a entrada deste sujeito neste local. O acolhimento visa resgatar princípios fundamentais, como a humanidade, o cuidado e a própria integralidade, além de buscar a qualificação dos trabalhadores do serviço para 
que estes se relacionem com os usuários pautados em parâmetros humanitários, de solidariedade e cidadania. Consequentemente são considerados aspectos físicos, biológicos, espirituais e emocionais do ser cuidado, fazendo com que o grupo se reorganize para atender às necessidades do sujeito. Desta forma, o cuidado, na perspectiva da integralidade, inclui as chamadas tecnologias leves, as quais envolvem as relaçôes entre os sujeitos e o acolhimento, gerando o vínculo nas relaçôes (SENA; SILVA, 2008).

No cuidado, é fundamental, então, que se enxergue além, isto é, o cuidado se constrói nas relaçôes terapêuticas, em que se considera o processo de saúde e doença como impactantes na condiçáo de vida do indivíduo (AYRES, 2004). Segundo Bechelli e Santos (2005), em um grupo, o coordenador tenta facilitar a participação e a interação dos membros, de forma que eles possam verbalizar seus pensamentos e emoções. Logo, quando o coordenador do grupo e os próprios integrantes ouvem com sensibilidade cada componente e o ambiente torna-se seguro e confiável, os participantes revelam-se em um nível mais profundo, o que aumenta a possibilidade de se compreender e modificar a percepção de si próprio. A partir deste momento, os participantes se integram, formam-se os vínculos de cuidado e processos de identificação, e os integrantes passam a trabalhar juntos, buscando soluçôes em conjunto (BECHELLI; SANTOS, 2005).

Cabe salientar que o grupo como espaço de cuidado também se configura nos momentos de orientaçóes aos integrantes e discussóes. Nos relatos a seguir, pode-se observar como os participantes veem as orientaçóes, exercícios e atividades desenvolvidas pelos profissionais como processo de cuidado, aprendizagem e busca por transformaçōes:

"O grupo ajuda bastante a gente neste sentido, pelas orientaçôes que a gente recebe das terapeutas ocupacionais e, volto a frisar, dos outros pacientes também" (Carlos).

"Foi aos poucos que eu fui vendo que a participação, que as atividades, as músicas, as danças, as entrevistas, sabe, as meninas da faculdade, cada turma e a gente, elas passaram coisas diferentes para a gente e a gente passou também coisas para elas" (Fátima).

Além disso, alguns participantes reconheceram e destacaram que as orientaçôes eram muitas vezes repassadas pelas profissionais e estagiárias, mas também tinham origem nas experiências dos próprios colegas:

"Eu atribuo essas mudanças aos exemplos que eu vejo aqui. Um chega e fala uma coisa: 'ah, eu fiz isso, e me dei muito bem', aí você tenta fazer também" (Irene).

"Eles (estagiárias, terapeutas ocupacionais) explicam com exemplos. Eu consigo, assim, aprender com eles, os exemplos que eles passam pra gente" (Luzia).

"Os coordenadores do grupo mostravam como a gente devia mexer a comida, como pegar um tabuleiro, até como deitar, o travesseiro tem que ser da altura do pescoço, náo pode ser aquele travesseiro alto, porque senão o pescoço dói” (Maria).

Outro aspecto importante a ser analisado, é como os participantes, ao entrarem em contato com as orientações, informaçóes e exemplos, levaram o conhecimento adquirido no grupo para o cotidiano:

"Porque as atividades que eu aprendi aqui eu posso fazer em casa, né. Colocar a lata de arroz, açúcar, ao invés de colocar no alto eu coloco no baixo, onde fica mais fácil pra mim. Eu não fazer as minhas atividades tudo de uma vez, eu fazer por etapas e descansar!" (Heloísa).

"Me ajudou assim, no meu fazer as minhas coisas de casa, como eu adaptar as minhas coisas no dia a dia, , até mesmo na maneira de eu me comportar, que antes eu chegava no grupo e eu não... mal conversava, eu ficava até com vergonha de conversar com as pessoas" (Rosa).

"Bem, eu faço as mesmas coisas só que de uma maneira diferente. Eu pegava uma panela, botava força pra pegar tudo com uma mão, agora não! Coloquei mais pano pra pegar, pra abraçar a panela assim, eu pego o cabo da panela com essa mão e no outro lado. Se for uma panela de pressão, pra despejar alguma comida eu sofria pra fazer isso, aí eu já não faço, peço o meu marido pra ajudar" (Luzia).

A partir do momento em que o participante se engaja ativamente no grupo, ele passa a processar as informaçóes que recebe (orientaçóes, exemplos), analisando-as para promover a mudança que deseja, ou seja, ele torna-se proativo na elaboração de ações em seu benefício e o coordenador do grupo assume o lugar de facilitador (BECHELLI; SANTOS, 2002; CARVALHO; NOORDHOEK; SILVA, 2006). O grupo assiste e promove a mudança e, com o maior envolvimento e interesse do participante no grupo, podem ser observados aspectos como redução da dor, maior capacidade de se enfrentar a doença, maior senso de competência durante realização de atividades cotidianas, aumento da socializaçâo, dentre outros (CARVALHO; NOORDHOEK; SILVA, 2006). Consequentemente, é fundamental pensar na importância da educação em saúde através do trabalho em grupo para a melhora da funcionalidade e da qualidade de vida. 
Benetton (2010) aponta que a mudança de hábitos deveria objetivar a inserção social e construir ou recuperar a dignidade da experiência e da ação cotidiana. Mas, para que este processo se concretize, é necessário conhecer o sujeito e seu cotidiano, o indivíduo nas suas atividades e relaçóes, ou seja, não apenas conhecer o diagnóstico médico ou o conjunto de sintomas, mas quem é o sujeito, o que ele faz e em que condiçóes (BENETTON, 2010). Desta forma, ao auxiliar o indivíduo na mudança de comportamentos diários, os profissionais de saúde náo só estariam lhe possibilitando realizar novas atividades, mas propondo que este sujeito pense em seu cotidiano, em seu significado e nos fatores limitantes para o desempenho das atividades diárias e para sua capacidade de se adaptar.

Este processo de educação em saúde e mudança de hábitos nem sempre acontece de forma linear e de modo fácil para os participantes. Nos fragmentos das narrativas destacados a seguir, podem ser observadas as mudanças vivenciadas pelos participantes após o ingresso no grupo. Essas mudanças envolvem a reorganização de hábitos, rotinas e papéis, assim como as dificuldades e facilidades apresentadas neste processo.

"No princípio não é muito fácil mudar hábitos. Porque tem que mudar de costume! Costume do dia a dia, diário, ali, saber que tem que mudar. (...) Não é só mudar de hábito, mas de opinião também, entendeu?" (Carlos).

"Tive dificuldade pra mudar meus hábitos. Às vezes a gente acostuma com um ritmo, e aquele ritmo ali você tem que parar, e perceber que aquele ritmo não está sendo certo pra você. Eu aprendi a repousar, eu descanso o meu corpo, se eu não descansar, meu corpo que reclama depois, quem vai sentir a dor depois vai ser eu. Então essa mudança de hábitos foi ótima, mas foi difícil” (Heloisa).

"O chão eu não esfrego mais, varrer eu varro, mas antes eu varria a casa todinha tudo num dia, aí eu aprendi aqui que deve ter limitação, que náo deve ser todo dia. Dois cômodos de cada vez, entendeu? $\mathrm{Eu}$ ando diferente, tipo assim, eu pus horário pra dividir as minhas coisas, não faço tudo ao mesmo tempo" (Luzia).

A partir destes fragmentos, observa-se que os participantes repensaram a forma como realizavam as suas atividades cotidianas. Os participantes apontam que antes do ingresso no grupo realizavam um número excessivo de atividades por dia, sem pausas ou divisão de tarefas, o que, por conseguinte, agravava os sintomas da condição crônica de saúde. Ao ingressarem no grupo e repensarem sua rotina e a forma de desempenhar as atividades do dia a dia, mudanças e reavaliação do comportamento diário foram desencadeadas. Por conseguinte, ao analisarem sua rotina, os participantes também repensaram e elaboraram, em grupo, novas formas de realizar as atividades:

"Mudei na forma de carregar uma sacola, eu carregava na mão, agora carrego sacola no braço, cotovelo, ombro. Mudou também a forma deu pegar na caneca e pra colocar o tabuleiro no forno, porque eu pegava assim, com a pontinha dos dedos, agora eu pego com a máo toda segurando" (Maria).

"Eu tive que fazer as minhas atividades dentro do meu limite para que eu não voltasse a sentir dor" (Fátima).

"Entâo, eu tive que adaptar algumas coisas, é claro, né?! Fechadura, por exemplo, maçanetas, aquelas roliças, eu troquei, né, por uma mais fácil de eu abrir. A blusa fechada que eu usava, no começo eu vestia uma mais folgada, pra me ajudar a vestir. (...) E o banho, eu tentava com os braços, com as mãos, sozinho esfregar as costas. Não Carlos! Você compra um escovão, você vai esfregar com o escovão" (Carlos).

Cabe destacar que os participantes, em conjunto, criaram novas estratégias para reorganizarem a rotina e a forma de executarem as atividades. Silva et al. (2011), em um estudo realizado com trabalhadores com dor crônica evidenciaram que esta condição clínica levou a restriçôes sociais, perdas de papéis e impacto no trabalho. No entanto, em resposta a estas rupturas advindas com o aparecimento da doença, os indivíduos também desenvolveram estratégias, aprenderam a lidar com a dor, reorganizaram a rotina diária, assim como formularam novos planos para o futuro. Todos estes aspectos tiveram como objetivo reconstruir suas histórias de vida e dar um novo significado às repercussóes da doença.

Assim, o conhecimento sobre a condição de saúde, o convívio com pessoas que vivenciam a mesma experiência, as atividades desenvolvidas no grupo, o aumento do senso de competência e autocuidado e, principalmente, o empoderamento do sujeito diante do seu processo de saúde tornaram-se facilitadores para o desenvolvimento destas mudanças (CARVALHO; NOORDHOEK; SILVA, 2006).

\subsection{Aprendendo a lidar com a condição de saúde}

Outro aspecto importante observado neste estudo e destacado na literatura é a forma como estes indivíduos lidam com o adoecimento. As doenças 
crônicas, em especial as doenças reumáticas, são condiçôes que influenciam de forma negativa a vida do indivíduo, desequilibrando suas relações interpessoais, sociais, ocupacionais e sentimentais. As possíveis deformidades ocasionadas pela condição de saúde e a dependência de outra pessoa para realizar atividades cotidianas podem ser fatores que influenciam o afastamento do paciente de relaçóes sociais mais amplas com a intenção de se proteger de estigmas e atitudes de preconceito (VANDENBERGHE; FERRO, 2005; SILVA et al., 2011).

"Que antes eu tinha vergonha de ter as minhas dificuldades, eu ficava com vergonha de pedir ajuda, eu... até mesmo pros meus filhos eu tinha dificuldade. (...) A vergonha de ter minhas tarefas e não conseguir realizá-las, vergonha dos outros ver meus problemas. Eu escondia a minha mão, por ela estar assim, com deformidades, eu tinha vergonha" (Heloisa).

Viana et al. (2007), demonstraram que a adaptação a uma condiçáo crônica pode ser afetada por fatores psicológicos e que o modo como o paciente enfrenta os problemas advindos do adoecimento deve ser considerado, uma vez que este enfrentamento da doença interfere no seu bem-estar. Durante as narrativas, foram encontradas várias respostas a estas dificuldades ou tentativas de aprender a viver ou conviver com a doença, como o desenvolvimento de estratégias de enfrentamento para lidar com as incapacidades e reorganizar o cotidiano. Estas estratégias são influenciadas pelo contato social das pessoas, natureza dos sintomas, percepçáo das pessoas acerca delas mesmas, olhar do outro, características pessoais e contexto, recursos socioecológicos e, ainda, pela interação entre todos estes fatores (BURY, 1991; ANTONIAZZI; DELL'AGLIO; BANDEIRA, 1998). Segundo Silva et al. (2011), as estratégias de enfrentamento são respostas aos efeitos da doença crônica e não significam apenas a habilidade da pessoa manipular o ambiente ou minimizar o impacto da doença, mas também a tentativa de mobilizar recursos para melhorar e estabelecer metas realistas para manutenção da vida diária.

Neste sentido, os grupos podem auxiliar no desenvolvimento de estratégias de enfrentamento modificando as implicaçóes de uma doença crônica e os significados que este fator estressor traz para o indivíduo, propiciando oportunidades de mudanças comportamentais e reorganização do cotidiano (VANDENBERGHE; FERRO, 2005). Os integrantes do grupo traçaram novas perspectivas e mudanças. Fátima, em seu relato, demonstra como transformou sua visão em relação à doença quando passou a escutar relatos de outros participantes:
"Quando eu entrei era um absurdo, eu perto delas não tinha nada. Então isso começou a trabalhar a minha cabeça" (Fátima).

Magda também modificou sua forma de lidar com a doença depois de ingressar no grupo e atualmente auxilia os participantes novatos a compreender e enfrentar a sua condição:

"E os participantes do grupo me ajudaram, porque desde o primeiro dia que eu cheguei aqui fui muito bem recebida, e tô sendo. E é uma coisa que a gente nem sabe explicar. Só sei que eles são muito bons pra mim. Eles dáo muitos exemplos da vida deles, principalmente assim, no sofrimento, uns têm uma dificuldade, outros sentem de um jeito, outros sentem de outro, é por aí que foi me ajudando mesmo. Hoje eu já consigo dar o exemplo pros que chegam. Que é preciso mudar" (Magda).

Internamente ao grupo, as trocas de experiências e a exposição de diferentes ideias e pontos de vista podem ajudar a modificar pensamentos catastróficos e crenças disfuncionais, assim como na elaboraçáo e treino de habilidades de enfrentamento (VANDENBERGHE; FERRO, 2005). Martins et al. (2005) apontam que ações em saúde e compartilhamento de vivências e saberes são realizados entre os usuários e profissionais, e, juntos, estes elaboram estratégias e objetivos a partir da descoberta de suas necessidades, o que norteia a prática na direção da realidade do sujeito.

As estratégias utilizadas por cada participante e que são trazidas para o grupo contribuem na forma de lidar com a doença e com as relaçóes interpessoais, assim como no enfrentamento das limitaçôes que podem estar presentes. Todo o processo que envolve o grupo torna-se ferramenta que contribui, de forma plural, para a promoção de discussão sobre saberes e fazeres em saúde, rompendo com o modelo unilateral (MARTINS et al., 2005). A discussão elaborada a partir de materiais, informaçóes e atividades desenvolvidas pelo terapeuta e pelos participantes se constitui em outra oportunidade de influenciar as estratégias de enfrentamento do grupo. Bernstein et al. (1994) apontam que a capacidade de enfrentamento está ligada a "ganho de poder", ou seja, à habilidade de agir e realizar modificaçôes em uma direçáo desejada.

"Depois desse tempo todo no grupo, hoje eu estou primeiramente conformado, né? E hoje eu sei conviver com ela (doença), de uma maneira confortável. E com as orientaçóes que a gente recebe aqui a gente tá dando pra adaptar a vida, não só adaptação física, mas na opinião também e não teimar em querer fazer uma coisa que náo dá” (Carlos). 
"Aí entrei aqui, aprendi um tanto de coisa com o pessoal todo, vê que os problemas das pessoas às vezes é pior do que o seu. Entáo você passa a encarar diferente. Assim, não tem que ter tanto sofrimento, dificuldades sim, né, mas náo tanto sofrimento" (Luzia).

Além disso, no nível emocional o grupo proporciona uma assistência na elaboração dos sentimentos presentes no momento e contribui para que o indivíduo consiga suportar suas emoçóes, compreender seus sentimentos e se torne mais apto a encontrar formas de lidar com a doença crônica, além de identificar, em seu cotidiano, aqueles fatores que reforçam o sofrimento (VANDENBERGHE; FERRO, 2005). O enfrentamento se insere no campo da promoção de saúde como uma estratégia que possibilita o ganho de saúde, visto que se reconhece que a ausência da capacidade de enfrentamento torna-se fator de risco para o adoecimento (TEIXEIRA, 2002).

Desta forma, observa-se que o grupo torna-se fonte de descoberta de estratégias de enfrentamento, no que se refere ao processo de mobilizaçóes e práticas para promover e impulsionar os integrantes no sentido do crescimento, da autonomia, da melhora progressiva de suas vidas (GOHN, 2004). Assim, os indivíduos buscam "normalizar" suas vidas, minimizando os impactos da condição crônica e desenvolvendo estratégias para preservar suas identidades (SILVA et al., 2011).

\section{Considerações finais}

Ao observar e analisar todos os relatos anteriormente expostos, foi possível documentar informaçóes sobre o impacto da doença crônica no cotidiano dos indivíduos, a percepçáo destes sobre as mudanças de comportamentos diários resultantes da sua participação em um grupo e, em especial, a importância do grupo neste processo de mudanças. Ressalta-se como o grupo tornou-se fonte de educação em saúde, através das orientaçôes, exemplos, convivência e envolvimento, promovendo momentos de reflexáo que contribuíram para a modificaçấo de comportamentos diários. O grupo assumiu significados distintos, como espaço de socializaçáo e lazer, de cuidado, espaço para a fomentaçáo da necessidade de mudança e como lugar para o entendimento das diferentes formas de lidar com o adoecimento, tendo em vista as limitaçôes e restriçôes apresentadas por cada integrante.

Neste contexto, pode-se apreender os benefícios da educação em saúde para o paciente crônico através de um modelo grupal de intervenção, no qual o espelhamento no outro tornou-se fonte de reflexão e de mudanças. A partir do momento em que os integrantes do grupo compreenderam sua condição clínica, suas limitações e potencialidades, estes passaram a enfrentar os problemas advindos da doença crônica e tornaram-se agentes ativos da própria mudança. Assim, o grupo tornou-se lócus importante para a reconstrução da vida de cada participante, auxiliando-os na identificação dos problemas e limitaçóes advindos com o adoecimento e, posteriormente, no desenvolvimento de estratégias de enfrentamento, capazes de proporcionar a reorganização da vida diária. Estas estratégias estimularam cada integrante na busca da autonomia, no resgate do senso de competência e na melhora progressiva da sua funcionalidade e qualidade de vida, através de mudanças que se estenderam ao bem-estar físico e psíquico.

\section{Referências}

ANTONIAZZI, A. S.; DELL'AGLIO, D. D.; BANDEIRA, D. R. O conceito de coping: uma revisão teórica. Estudos de Psicologia, v. 3, n. 2, p. 273-94, 1998. http://dx.doi. org/10.1590/S1413-294X1998000200006

ASSUMPÇÃO, T.; CAVALCANTI, A.; SILVA, P. Doenças reumáticas. In: CAVALCANTI, A.; GALVÃO, C. Terapia Ocupacional: fundamentação e prática. Rio de Janeiro: Guanabara Koogan, 2007. p. 238-46.

AYRES, J. R. Cuidado e reconstrução das práticas de saúde. Interface-Comunicação, Saúde, Educação, v. 8 , n. 14, p. 73-92, 2004. http://dx.doi.org/10.1590/ S1414-32832004000100005

BARDIN, L. Análise de conteúdo. Lisboa: Ediçōes 70, 1979.

BECHELLI, L.; SANTOS, M. O paciente na psicoterapia de grupo. Revista Latino americana de Enfermagem, v. 13, n. 1, p. 118-25, 2005. PMid:15761590. http://dx.doi. org/10.1590/S0104-11692005000100019

BECHELLI, L.; SANTOS, M. Psicoterapia de grupo e consideraçôes sobre o paciente como agente da própria mudança. Revista Latino americana de Enfermagem, v. 10, n. 3, p. 383-91, 2002. PMid:12817392. http://dx.doi. org/10.1590/S0104-11692002000300012

BENETTON, J. O encontro do sentido do cotidiano na Terapia Ocupacional para a construção de significados. Revista Ceto, ano 12, n. 12, p. 32-39, 2010.

BERNSTEIN, E. et al. Empowerment forum: a dialogue between guest editorial board members. Health Education Quarterly, v. 21, n. 3, p. 281-294, 1994. Special issue. Community empowerment, participatory education and health - Part II. http://dx.doi. org/10.1177/109019819402100302

BOTTEGA, F.; FONTANA, R. A dor como quinto sinal vital: utilização da escala de avaliação por enfermeiros de um hospital geral. Texto Contexto Enfermagem, 
v. 19, n. 2, p. 283-90, 2010. http://dx.doi.org/10.1590/ S0104-07072010000200009

BRASIL. Ministério da Saúde. Ato Portaria no 19/GM, de 03 de janeiro de 2002. Institui o Programa Nacional de Assistência à Dor e Cuidados Paliativos, do Sistema Único de Saúde - SUS. Diário Oficial da República Federativa do Brasil, Poder Executivo, Brasília, DF, 8 jan. 2002. Seção 1, p. 1. Disponível em: <http://dtr2001.saude.gov. br/sas/PORTARIAS/Port2002>. Acesso em: 15 jan. 2011

BURY, M. The sociology of chronic illness: a review of research and prospects. Sociology of Health and Illness, v. 13, n. 4, p. 451-468, 1991. http://dx.doi. org/10.1111/j.1467-9566.1991.tb00522.x

CABRAL, M. V.; MONTANDON, A. C.; SILVA, N. A. Doenças osteoarticulares degenerativas periféricas. Revista Einstein, v. 6, p. 25-28, 2008. Suplemento 1.

CARVALHO, M.; NOORDHOEK, J.; SILVA, M. Grupo de orientação a indivíduos acometidos por doenças reumáticas: espaço educativo e terapêutico. Revista Brasileira de Reumatologia, v. 46, n. 2, p. 134-136, 2006. http://dx.doi.org/10.1590/S0482-50042006000200008 COSTA, C. T. Percepção de Liberdade no Lazer: perspectiva dos trabalhadores de saúde mental dos Centros de Referência e Centros de Convivência do Município de Belo Horizonte - Brasil. 2008. 193 f. Dissertação (Mestrado em Ciência dos Desportos)-Faculdade de Desporto, Universidade do Porto, Porto, 2008.

DUMAZEDIER, J. Lazer e cultura popular. São Paulo: Perspectiva, 1976.

FEIRENBERG, J. R.; TROMBLY, C. A. Arthritis. In: TROMBLY, C. A. Occupational Therapy for physical dysfunction. 4. ed. Baltimore: Willians \& Wilkins, 1995. p. $815-830$.

FORTES, S. L. Grupos com pacientes com dor crônica. In: MELLO FILHO, J. et al. Grupo e corpo: psicoterapia de grupo com pacientes somáticos. São Paulo: Artmed, 2000. cap. 22, p. 331-343.

GOHN, M. Empoderamento e participação da comunidade em políticas sociais. Saúde e Sociedade, v. 13, n. 2, p. 20-31, 2004.

HENNINGTON, E. Acolhimento como prática interdisciplinar num programa de extensão universitária. Cadernos de Saúde Pública, v. 21, n. 1, p. 256-65, 2005. http://dx.doi.org/10.1590/S0102-311X2005000100028

KERKOSKI, E. et al. Grupo de convivência com pessoas com doença pulmonar obstrutiva crônica: sentimentos e expectativas. Texto Contexto Enfermagem, v. 16, n. 2, p. 225-32, 2007. http://dx.doi.org/10.1590/ S0104-07072007000200003

KRELING, M.; CRUZ, D.; PIMENTA, C. Prevalência de dor crônica em adultos. Revista Brasileira de Enfermagem, v. 59, n. 4, p. 509-13, 2006. PMid:17340726. http:// dx.doi.org/10.1590/S0034-71672006000400007

LAURINDO, I. et al. Consenso brasileiro para o diagnóstico e tratamento da artrite reumatóide. Revista Brasileira de Reumatologia, v. 42, n. 6, p. 355-361, 2002.
LOSCHIAVO, F.; NOORDHOEK, J. A intervenção da terapia ocupacional no tratamento de indivíduos com doenças reumáticas utilizando a abordagem da proteção articular. Revista Brasileira de Reumatologia, v. 45, n. 4, p. 242-44, 2005

MARCON, S. et al. Vivência e reflexões de um grupo de estudos junto às famílias que enfrentam a situação crônica de saúde. Texto Contexto Enfermagem, v. 14, p. 116-24, 2005. Número especial. http://dx.doi. org/10.1590/S0104-07072005000500015

MARTINS, M. et al. A trajetória do grupo de apoio à pessoa ostomizada: projetando açóes em saúde e compartilhando vivências e saberes. Texto Contexto Enfermagem, v. 14, n. 4, p. 594-600, 2005.

MERLO, A. R.; JACQUES, M. G.; HOEFEL, M. G. Trabalho de grupo com portadores de Ler/Dort: relato de experiência. Psicologia: Reflexão e Crítica, v. 14, n. 1, p. 253-258, 2001. http://dx.doi.org/10.1590/ S0102-79722001000100021

MERSKEY, H.; BOGDUK, N. Classification of chronic pain-descriptions of chronic pain syndromes and definitions of pain terms. 2. ed. Seattle: International Association for the Study of Pain Press, 1994.

MINAYO, M. C. O desafio do conhecimento: pesquisa qualitativa em saúde. 8. ed. Sáo Paulo: Hucitec, 2004.

ORGANIZAÇÃO MUNDIAL DE SAÚDE - OMS. Preventing chronic diseases: a vital investment. Genebra: OMS, 2005. 182 p.

SANTOS, L. M. et al. Grupos de promoção à saúde no desenvolvimento da autonomia, condições de vida e saúde. Revista de Saúde Pública, v. 40, n. 2, p. 346-52, 2006. http://dx.doi.org/10.1590/S0034-89102006000200024 SILVA, F. C. et al. A Qualitative Study of Workers with Chronic Pain in Brazil and its Social Consequences. Occupational Therapy International, v. 18, n. 2, p. 85-95. 2011. PMid:20872907. http://dx.doi.org/10.1002/ oti.302

SENA, R.; SILVA, K. Integralidade do cuidado na saúde: indicaçôes a partir da formação do enfermeiro. Revista da Escola de Enfermagem - USP, v. 42, n. 1, p. 48-56, 2008. PMid:18450147.

TEIXEIRA, M. Empoderamento de idosos em grupos direcionados à promoção da saúde. 2002. 144 f. Dissertação (Mestrado em Saúde Pública)-Escola Nacional de Saúde Pública, Fundação Oswaldo Cruz, Rio de Janeiro, 2002.

VANDENBERGHE, L; FERRO, C. L. B. Terapia de grupo embasada em psicoterapia analítica funcional como abordagem terapêutica para dor crônica: possibilidades e perspectivas. Revista de Psicologia: Teoria e Prática, v. 7, n. 1, p. 137-151, 2005.

VIANA, S. O. et al. Life Satisfaction of Workers with Work-related Musculoskeletal Disorders in Brazil: Associations with Symptoms, Functional Limitation and Coping. Journal of Occupational Rehabilitation, v. 17, n. 1, p. 33-46, 2007. PMid:17235678. http://dx.doi. org/10.1007/s10926-006-9062-z 
WORLD LEISURE AND RECREATION ASSOCIATION - WLRA. Carta Internacional de educaçäo para o lazer. Jerusalém: WLRA, 1993. Disponível em: <http://www.saudeemmovimento.com.br/conteudos/ conteudo_exibe1.asp?cod_noticia=195>. Acesso em: 06 out. 2011.
YASUDA, Y. L. Artrite Reumatóide e Osteoartrite. In: RADOMSKI, M. V.; TROMBLY, C. A. Terapia Ocupacional para disfunçōes físicas. 5. ed. São Paulo: Santos, 2005. p. 1001-24.

\section{Contribuição dos Autores}

Alessandra Antunes Tavares e Luciana Mata de Freitas foram responsáveis pela concepção, pesquisa, metodologia e redação. Fabiana Caetano Martins Silva foi responsável pela orientação da pesquisa e redação. A revisão final e co-orientação foram realizadas por Rosana Ferreira Sampaio. 